\title{
Comparison of Meteoroid Flux Models for Near Earth Space
}

\author{
Gerhard Drolshagen · Valeri Dikarev · Markus Landgraf · Holger Krag • \\ Wim Kuiper
}

Received: 17 August 2007/ Accepted: 19 November 2007/Published online: 13 December 2007

(C) Springer Science+Business Media B.V. 2007

\begin{abstract}
Over the last decade several new models for the sporadic interplanetary meteoroid flux have been developed. These include the Divine-Staubach and the Dikarev model. They typically cover mass ranges from $10^{-18} \mathrm{~g}$ to $1 \mathrm{~g}$ and are applicable for model specific Sun distance ranges between 0.1 AU and 20 AU Near 1 AU averaged fluxes (over direction and velocities) for all these models are tuned to the well established interplanetary model by Grün et al. However, in many respects these models differ considerably. Examples are the velocity and directional distributions and the assumed meteoroid sources. In this paper flux predictions by the various models to Earth orbiting spacecraft are compared. Main differences are presented and analysed. The persisting differences even for near Earth space can be seen as surprising in view of the numerous ground based (optical and radar) and in situ (captured Inter Stellar Dust Particles, in situ detectors and analysis of retrieved hardware) measurements and simulations.
\end{abstract}

Keywords Meteoroids - Meteoroid Flux models · Near Earth space · Interplanetary meteoroid models - Space dust - IMEM - Divine model · Divine-Staubach model $\cdot$ Impact flux

G. Drolshagen $(\bowtie) \cdot$ W. Kuiper TEC-EES, ESA/ESTEC, Keplerlaan 1, 2201 AZ Noordwijk, The Netherlands e-mail: gerhard.drolshagen@esa.int

V. Dikarev

MPI For Solar System Research, Katlenburg-Lindau, Germany

M. Landgraf · H. Krag

ESA/ESOC, Darmstadt, Germany

W. Kuiper

RheaTech Ltd., London, UK 


\section{Introduction}

Any assessment of particle impact risks to spacecraft in orbit requires reliable meteoroid population models. Over the last decade, new models for the sporadic interplanetary meteoroid flux have been developed. These models cover the full velocity range and particle diameters from sub-microns to $\mathrm{cm}$.

In this paper, flux predictions by the various models to Earth orbiting spacecraft are compared. The main focus is on the velocity and directional distributions and the implemented meteoroid sources. Main differences are presented and discussed.

\subsection{Model Description}

Several models, each having their own population source characteristics, are used for the comparison. An overview is given in Table 1.

The Grün interplanetary flux model (Grün et al. 1985) assumes an isotropic meteoroid distribution which is based on lunar crater, zodiacal light and in situ measurement data. For the conversion of crater sizes to particle masses, a constant velocity of $20 \mathrm{~km} / \mathrm{s}$ was used. The Grün model is frequently used with added velocity distributions, such as from SSP 30425 (Kessler et al. 1994) or Taylor (Taylor 1995), to include directional effects. SSP 30425 is a velocity distribution, developed for the International Space Station. Therefore, it is valid for Low Earth Orbits (LEO) only. Taylor used data from the Harvard Radio Meteor Project (HMRP) to develop a velocity distribution, which is valid for near Earth orbits and the interplanetary space near $1 \mathrm{AU}$.

The Divine interplanetary model (Divine 1993) was one of the first models with nonisotropic distributions. The model is based on five different populations each having separable distributions in particle mass, inclination, eccentricity, and perihelion distance.

Staubach (Staubach et al. 1996; Grün et al. 1997) upgraded Divine's model using new data from GALILEO and ULYSSES dust detectors. Solar radiation pressure was added as a second perturbation force and an additional population, Inter Stellar Dust (ISD), was implemented.

With the IMEM/Dikarev model (Dikarev et al. 2005a, b, c), an attempt was made to construct a meteoroid model, based on the physical effects that influence meteoroid orbit and sources, in addition to fitting model predictions to observations. The ISD population was adopted from the Divine-Staubach model, with a re-normalisation to take additional ULYSSES dust detector data into account.

\subsection{Test Cases}

The different meteoroid models are compared for LEO (400 km circular or bit and 51.6 inclination) and Geostationary orbit (GEO). First the flux to a Randomly Tumbling Plate

Table 1 Meteoroid models used for comparison

\begin{tabular}{llll}
\hline Meteoroid model & Year of release & Applicable mass domain & Applicable regime \\
\hline Grün et al. & 1985 & $10^{-18}-100 \mathrm{~g}$ & Around 1 AU from sun \\
Divine & 1993 & $10^{-18}-1 \mathrm{~g}$ & $0.1-20$ AU from sun \\
Divine-Staubach & 1996 & $10^{-18}-1 \mathrm{~g}$ & $0.1-20$ AU from sun \\
IMEM/Dikarev & 2003 & $10^{-18}-1 \mathrm{~g}$ & $0.1-10$ AU from sun \\
\hline
\end{tabular}




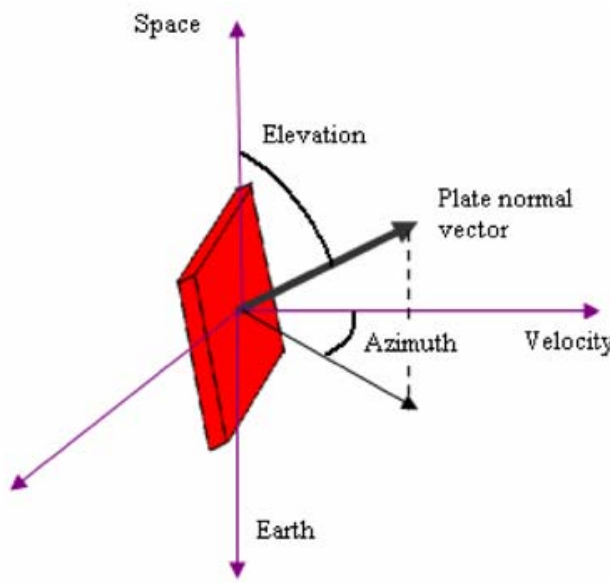

\begin{tabular}{|r|cc|}
\cline { 2 - 3 } \multicolumn{1}{c|}{} & Azimuth $\left[{ }^{\circ}\right]$ & Elevation $\left[{ }^{\circ}\right]$ \\
\hline Ram & 0 & 90 \\
Starboard & 90 & 90 \\
Wake & 180 & 90 \\
Space & 0 & 0 \\
\hline
\end{tabular}

Fig. 1 Definition of reference frame and orientations

(RTP) is predicted for a mass range of $10^{-15}-1 \mathrm{~g}$. More detailed information is obtained by comparing the directional dependence of the models. For two mass thresholds, $10^{-12} \mathrm{~g}$ and $10^{-3} \mathrm{~g}$, the flux from all models is predicted for oriented plates facing towards ram, starboard, wake and space, respectively (see Fig. 1 for definition of orientations).

Finally, normalised velocity distributions are compared for both orbits and different mass thresholds.

\section{Results}

The results for the RTP analysis are shown in Fig. 2. The calculated fluxes include the effects from Earth shielding and gravitational attraction. The model by Grün et al. has been combined with the Taylor/HRMP velocity distribution. All fluxes are for an orbiting spacecraft in a $400 \mathrm{~km}$ LEO.

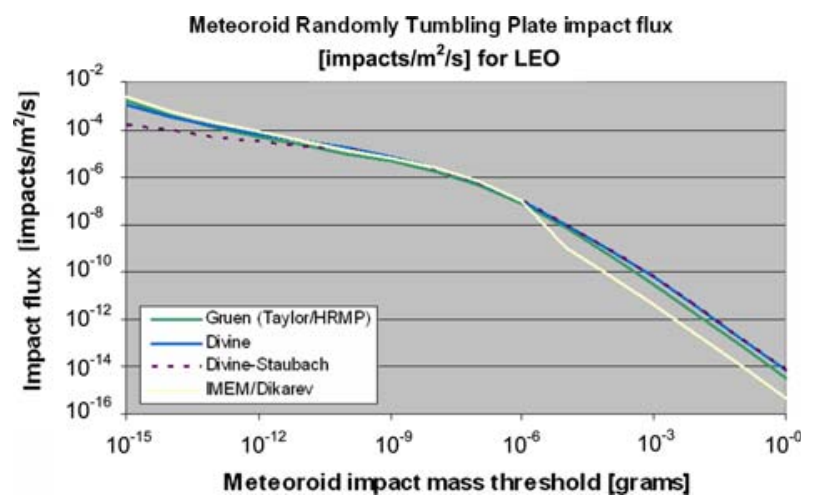

Fig. 2 Predicted meteoroid fluxes to one side of a randomly tumbling plate in LEO 
The flux predictions to a RTP agree quite well for all models. This is not really surprising as all models analysed have fitted the random plate flux near $1 \mathrm{AU}$ to the interplanetary model by Grün et al. In the low mass regime $\left(<10^{-12} \mathrm{~g}\right)$, the DivineStaubach model is predicting lower fluxes compared to the other models. The Dikarev model predicts lower fluxes for meteoroid masses larger than $10^{-5} \mathrm{~g}$. In the Dikarev model, flux results are based on crater volume, which is proportional to the kinetic energy of impacting particles. The IMEM/Dikarev model assumes higher impact velocities for the larger masses than the $20 \mathrm{~km} / \mathrm{s}$ which were assumed by Grün et al. To be consistent with the crater data used by Grün et al. this leads to lower fluxes for a given fixed mass compared with the Grün model.

Tables 2-5 give predicted fluxes for orbiting surfaces with four different fixed orientations relative to the spacecraft velocity vector.

Directional effects result from model characteristics and from the orbital motion of the spacecraft. All models predict the highest flux for the ram facing surface and the lowest for the wake direction. Similar to the RTP analysis, the fluxes from the Divine-Staubach and IMEM/Dikarev models differ from those predicted by the other models at certain mass regimes.

Table 2 Directional dependence for $\mathrm{m} \geq 10^{-12} \mathrm{~g}$ in LEO

\begin{tabular}{lllll}
\hline Flux [impacts $/ \mathrm{m}^{2} / \mathrm{s}$ ] for $\mathrm{m} \geq 10^{-12} \mathrm{~g}$ and LEO & & & \\
\hline Model & Ram & Starboard & Zenith & Wake \\
\hline Grün (Taylor/HRMP) & $1.09 \mathrm{E}-04$ & $5.13 \mathrm{E}-05$ & $7.48 \mathrm{E}-05$ & $1.53 \mathrm{E}-05$ \\
Divine & $1.41 \mathrm{E}-04$ & $8.31 \mathrm{E}-05$ & $9.55 \mathrm{E}-05$ & $1.67 \mathrm{E}-05$ \\
Divine-Staubach & $6.66 \mathrm{E}-05$ & $5.18 \mathrm{E}-05$ & $5.04 \mathrm{E}-05$ & $1.38 \mathrm{E}-05$ \\
IMEM/Dikarev & $1.79 \mathrm{E}-04$ & $1.01 \mathrm{E}-04$ & $1.28 \mathrm{E}-04$ & $2.03 \mathrm{E}-05$ \\
\hline
\end{tabular}

Table 3 Directional dependence for $\mathrm{m} \geq 10^{-3} \mathrm{~g}$ in LEO

\begin{tabular}{llllr}
\hline Flux [impacts $\left./ \mathrm{m}^{2} / \mathrm{s}\right]$ for $\mathrm{m} \geq 10^{-3} \mathrm{~g}$ and LEO & & & \\
\hline Model & Ram & Starboard & Zenith & Wake \\
\hline Grün (Taylor/HRMP) & $5.98 \mathrm{E}-11$ & $2.82 \mathrm{E}-11$ & $4.10 \mathrm{E}-11$ & $8.40 \mathrm{E}-12$ \\
Divine & $1.27 \mathrm{E}-10$ & $6.50 \mathrm{E}-11$ & $8.19 \mathrm{E}-11$ & $8.60 \mathrm{E}-12$ \\
Divine-Staubach & $1.27 \mathrm{E}-10$ & $6.50 \mathrm{E}-11$ & $8.19 \mathrm{E}-11$ & $8.59 \mathrm{E}-12$ \\
IMEM/Dikarev & $8.55 \mathrm{E}-12$ & $9.98 \mathrm{E}-13$ & $6.86 \mathrm{E}-12$ & $2.02 \mathrm{E}-12$
\end{tabular}

Table 4 Directional dependence for $\mathrm{m} \geq 10^{-12} \mathrm{~g}$ in GEO

\begin{tabular}{llllr}
\hline Flux [impacts $/ \mathrm{m}^{2} / \mathrm{s}$ ] for $\mathrm{m} \geq 10^{-12} \mathrm{~g}$ and GEO & & & \\
\hline Model & RAM & Starboard & Zenith & Wake \\
\hline Grün (Taylor/HRMP) & $5.78 \mathrm{E}-05$ & $4.10 \mathrm{E}-05$ & $4.05 \mathrm{E}-05$ & $2.72 \mathrm{E}-05$ \\
Divine & $7.77 \mathrm{E}-05$ & $4.95 \mathrm{E}-05$ & $4.92 \mathrm{E}-05$ & $2.69 \mathrm{E}-05$ \\
Divine-Staubach & $4.62 \mathrm{E}-05$ & $1.82 \mathrm{E}-05$ & $3.34 \mathrm{E}-05$ & $2.31 \mathrm{E}-05$ \\
IMEM/Dikarev & $9.28 \mathrm{E}-05$ & $4.86 \mathrm{E}-05$ & $5.99 \mathrm{E}-05$ & $3.28 \mathrm{E}-05$ \\
\hline
\end{tabular}


Table 5 Directional dependence for $\mathrm{m} \geq 10^{-3} \mathrm{~g}$ in GEO

\begin{tabular}{lllll}
\hline Flux [impacts $/ \mathrm{m}^{2} / \mathrm{s}$ ] for $\mathrm{m} \geq 10^{-3} \mathrm{~g}$ and GEO & & & \\
\hline Model & RAM & Starboard & Zenith & Wake \\
\hline Grün (Taylor/HRMP) & $3.17 \mathrm{E}-11$ & $2.25 \mathrm{E}-11$ & $2.22 \mathrm{E}-11$ & $1.49 \mathrm{E}-11$ \\
Divine & $5.70 \mathrm{E}-11$ & $4.74 \mathrm{E}-11$ & $3.29 \mathrm{E}-11$ & $1.33 \mathrm{E}-11$ \\
Divine-Staubach & $5.70 \mathrm{E}-11$ & $4.74 \mathrm{E}-11$ & $3.29 \mathrm{E}-11$ & $1.33 \mathrm{E}-11$ \\
IMEM/Dikarev & $6.95 \mathrm{E}-12$ & $4.25 \mathrm{E}-12$ & $4.94 \mathrm{E}-12$ & $3.45 \mathrm{E}-12$ \\
\hline
\end{tabular}

The Divine and Divine-Staubach models predict equal fluxes for $\mathrm{m}>10^{-3} \mathrm{~g}$. The upgrade of the Divine model by Staubach only influences the lower meteoroid mass regime.

Figures 3 and 4 show the normalised velocity distributions for LEO and mass thresholds $\mathrm{m}>10^{-12} \mathrm{~g}$ and $\mathrm{m}>10^{-3} \mathrm{~g}$. The IMEM/Dikarev, Divine and Divine-Staubach models have a build-in velocity distribution resulting from the source terms. The distributions denoted by SSP 30425 and Taylor/HRMP can be used with the isotropic distribution of the Grün model. The rather artificial SSP 30425 distribution was developed for engineering purposes of the Space Station Programme. It was one of the earliest developments of a velocity distribution and never aimed at scientific accuracy.

The velocity distributions from the different models differ considerably. In the high $\left(>10^{-3} \mathrm{~g}\right)$ mass regime, the normalised velocity distribution graph for the IMEM/Dikarev model indeed peaks at higher impact velocities compared to the other models.

For the lower mass threshold, the velocity distributions of the Divine-Staubach and IMEM/Dikarev models have local maxima between $50 \mathrm{~km} / \mathrm{s}$ and $65 \mathrm{~km} / \mathrm{s}$. These result from the ISD population which makes a noticeable contribution for smaller masses. The magnitude of this ISD contribution and the impact velocity depends on the yearly season. The models for the ISD populations assume a fixed velocity of $26 \mathrm{~km} / \mathrm{s}$ relative to the sun and a fixed arrival direction in a sun-centered ecliptic reference system $\left(77^{\circ}\right.$ longitude and $-3^{\circ}$ latitude for IMEM/Dikarev). The impact fluxes and velocities of ISD particles are then determined by the motion of the ISD particles and the Earth relative to the sun. The additional spacecraft motion introduces the double peaks between $48 \mathrm{~km} / \mathrm{s}$ and $65 \mathrm{~km} / \mathrm{s}$ in Figs. 3 and 5. The results in Figs. 3-5 are for 21 March when the ISD contribution and

Fig. 3 Velocity distributions for LEO and $\mathrm{m}>10^{-12} \mathrm{~g}$

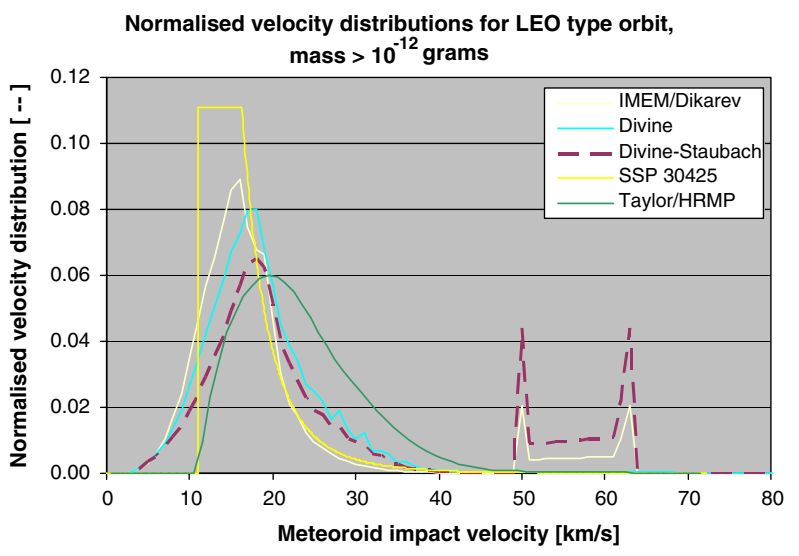


Fig. 4 Velocity distributions for LEO and $\mathrm{m}>10^{-3} \mathrm{~g}$
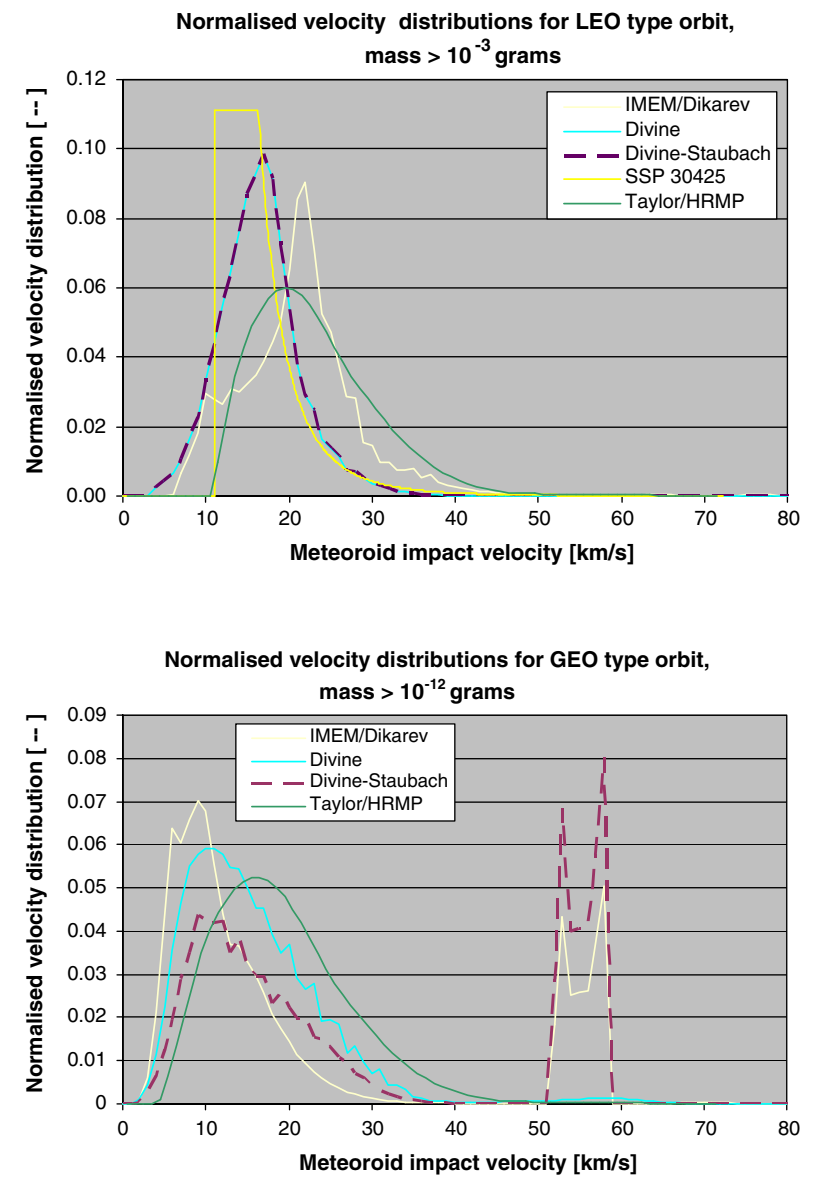

Fig. 5 Velocity distributions for GEO and $\mathrm{m}>10^{-12} \mathrm{~g}$

relative velocities are near maximum. The models also predict vanishing ISD fluxes for larger masses as is evident from the absence of this population for $\mathrm{m}>10^{-3} \mathrm{~g}$ (Fig. 4).

The normalised velocity distributions for GEO and $\mathrm{m}>10^{-12} \mathrm{~g}$ are presented in Fig. 5 .

Compared to LEO, the GEO distributions are shifted towards lower impact velocities. This is a direct result of the reduced gravitational attraction from Earth and lower spacecraft velocity in GEO. Velocity distributions for other mass thresholds show a similar behavior when compared for LEO and GEO.

\section{Conclusions}

The meteoroid fluxes predicted for randomly oriented plates in near Earth orbits agree well for all models. For these models, the measurement data from the vicinity of the Earth has been refitted-since this, to a large degree, overlaps with the data already used by Grün et al. the flux levels correspond well for the near Earth space. Some differences were found in the lower and higher meteoroid mass regimes. The IMEM/Dikarev model predicts lower meteoroid fluxes for the higher mass regime compared to the other models, which is a direct consequence of the higher velocities, assumed by this model. 
Directional and velocity distributions of the various models are quite different indicating persistent uncertainties. Differences for Sun distances away from $1 \mathrm{AU}$ will be larger still. Near Earth meteoroid flux predictions are validated by data sets from ground observations and in-flight measurements. At other interplanetary distances, these data sets become scarce and the discrepancies will become larger.

This paper did not perform an exhaustive comparison of all existing meteoroid models. The new MEM model (Jones 2004) is based on data from the Canadian CMOR radar. It is mainly based on cometary sources and applicable for the mass range $10^{-6}-10 \mathrm{~g}$ and for Sun distances between 0.2 AU and 2 AU.

Even near Earth increased efforts should be made to measure the full meteoroid population, including the complete range of velocities. Present optical and radar measurements of meteors are strongly dominated by the high velocity tail of the meteoroid population.

The present comparison of flux predictions near Earth from existing models shows a clear need for additional measurements and simulations in order to derive a reliable model for the population of interplanetary and interstellar meteoroids.

\section{References}

V. Dikarev, E. Grün, M. Landgraf, R. Jehn, Update of the ESA meteoroid model, in Proceedings of the 4th European Conference on Space Debris, (ESA SP-587, 2005a), pp. 271-277

V. Dikarev, E. Grün, J. Baggaley, D. Galligan, M. Landgraf, R. Jehn, The new ESA meteoroid model. Adv. Space Res. 35(issue 7), 1282-1289 (2005b)

V. Dikarev, E. Grün, J. Baggaley, D. Galligan, M. Landgraf, R. Jehn, Modeling the sporadic meteoroid background cloud. Earth Moon Planets 95, 109-122 (2005c)

N. Divine, Five populations of interplanetary meteoroids. J. Geophys. Res. 98, 17029-17048 (1993)

E. Grün, H.A. Zook, H. Fechtig, R.H. Giese, Collisional balance of the meteoritic complex. Icarus 62, 244 272 (1985)

E. Grün, P. Staubach, M. Baguhl, D.P. Hamilton, H.A Zook, S. Dermott, B.A. Gustafson, H. Fechtig, J. Kissel, D. Linkert, G. Linkert, R. Srama, M.S. Hanner, C. Polanskey, M. Horanyi, B.A. Lindblad, I. Mann, J.A.M McDonnell, G.E. Morfill, G Schwehm, South-North and radial traverses through the interplanetary dust cloud. Icarus 129(issue 2), 270-288 (1997)

J. Jones, Meteoroid engineering model-final report. NASA/MSFC internal report SEE/CR-2004, 400 (2004)

D.J. Kessler, R.C. Reynolds, P.D. Anz-Meador, Space station program natural environment definition for design, international space station alpha. NASA SSP 30425, Revision B, national aeronautics and space administration space station program office, Houston, TX, USA (1994)

P. Staubach, E. Grün, R Jehn, The meteoroid environment near Earth. Adv. Space Res. 19(issue 2), 301-308 (1996)

A.D. Taylor, The harvard radio meteor project meteor velocity distribution reappraised. Icarus 116, 154-158 (1995) 